Article

\title{
Discriminating Irrigated and Rainfed Maize with Diurnal Fluorescence and Canopy Temperature Airborne Maps
}

\section{Micol Rossini ${ }^{1, *}$, Cinzia Panigada ${ }^{1}$, Chiara Cilia ${ }^{1}$, Michele Meroni ${ }^{2}$, Lorenzo Busetto ${ }^{3}$, Sergio Cogliati ${ }^{1}$, Stefano Amaducci ${ }^{4}$ and Roberto Colombo ${ }^{1}$}

1 Remote Sensing of Environmental Dynamics Laboratory, Department of Earth and Environmental Science (DISAT), University of Milano-Bicocca, Piazza della Scienza 1, 20126 Milano, Italy; E-Mails: cinzia.panigada@unimib.it (C.P.); chiara.cilia@gmail.com (C.C.); sergio.cogliati@unimib.it (S.C.); roberto.colombo@unimib.it (R.C.)

2 European Commission, DG-JRC, Institute for Environment and Sustainability, Monitoring Agricultural Resources Unit-H04, 21027 Ispra, VA, Italy; E-Mail: michele.meroni@jrc.ec.europa.eu

3 Remote Sensing Department-IREA-National Research Council (CNR), Via Bassini 15, 20133 Milano, Italy; E-Mail: busetto.1@irea.cnr.it

4 Dipartimento di Scienze delle Produzioni Vegetali Sostenibili, Università Cattolica del Sacro Cuore, Via Emilia Parmense 84, 29122 Piacenza, Italy; E-Mail: stefano.amaducci@unicatt.it

* Author to whom correspondence should be addressed; E-Mail: micol.rossini@unimib.it; Tel.: +39-026-448-2848; Fax: +39-026-448-2895.

Academic Editors: Fei Yuan and Wolfgang Kainz

Received: 11 December 2014 / Accepted: 7 April 2015 / Published: 20 April 2015

\begin{abstract}
This study evaluates the potential of airborne remote sensing images to detect water stress in maize. Visible and near infrared CASI (Itres Research Ltd., Calgary, AL, Canada) and thermal AHS-160 (Sensytech Inc., Beverly, MA, USA) data were acquired at three different times during the day on a maize field (Zea mays L.) grown with three different irrigation treatments. An intensive field campaign was also conducted concurrently with image acquisition to measure leaf ecophysiological parameters and the leaf area index. The analysis of the field data showed that maize plants were experiencing moderate to severe water stress in rainfed plots and a weaker stress condition in the plots with a water deficit imposed between stem elongation and flowering. Vegetation indices including the normalized difference vegetation index (NDVI) and the photochemical reflectance index (PRI) computed from the CASI images, sun-induced chlorophyll fluorescence $\left(\mathrm{F}_{760}\right)$ and canopy temperature (Tc) showed different performances in describing the water stress during the day. During the
\end{abstract}


morning overpass, NDVI was the index with the highest discriminant power due to the sensitivity of NDVI to maize canopy structure, affected by the water irrigation treatment. As the day progressed, processes related to heat dissipation through plant transpiration became more and more important and at midday Tc showed the best performances. Furthermore, Tc retrieved from the midday image was the only index able to distinguish all the three classes of water status. Finally, during the afternoon, PRI and F760 showed the best performances. These results demonstrate the feasibility to detect water stress using thermal and optical airborne data, pointing out the importance of careful planning of the airborne surveys as a function of the specific aims of the study.

Keywords: diurnal; temperature; fluorescence; PRI; water stress; corn

\section{Introduction}

The prospects of water scarcity are increasing in many world areas [1] stimulating the development of techniques enabling an efficient use of water in agriculture. The minimization of water losses in agriculture is in fact a requisite to release water resources to other sectors of society where demand is increasing [2]. In Italy, maize (Zea mays, L.) is a crop widely cultivated and with large irrigation requirements. The timely assessment of maize water status is important for accurate irrigation scheduling and to avoid both waste of water and loss of crop yield.

Photosynthesis is among the primary processes affected by water stress as a result of both stomatal and non-stomatal (biochemical) limitations [3]. Stomata closure is a common mechanism used by plants to prevent leaf desiccation in response to water stress conditions. It generally occurs due to a decline in leaf turgor and atmospheric vapor pressure along with root-generated chemical signals causing a measurable reduction of leaf stomatal conductance to water vapor [4] and transpiration rate. The decrease in evaporative cooling causes an increase of vegetation temperature that can be tracked using thermal imagery $[5,6]$. The relationship between vegetation temperature and transpiration rates is affected by water stress experienced by the plants but also by environmental parameters, as the vapor pressure deficit of the air (VPD). The crop water stress index (CWSI) [7] has been proposed to normalize the difference between canopy temperature and air temperature $(\Delta \mathrm{T})$ by the evaporative demand. The CWSI can be computed based on an empirical approach relating $\Delta \mathrm{T}$ to the VPD of a "non-water-stressed baseline" referring to a well-watered crop transpiring at the potential rate (for a recent review refer to [8]).

Additionally, when photosynthesis is inhibited, as it is in water stress conditions, plants absorb more energy than can be used for photosynthesis. Plants react to such conditions activating protective mechanisms to avoid light-induced oxidative damage. These mechanisms consist in the dissipation of excess excitation energy as chlorophyll fluorescence and/or heat. Since these two occur in competition with photosynthesis, variations of the yield of chlorophyll fluorescence and heat dissipation have been exploited to detect stress-induced variations in photosystem II efficiency [9]. Both sun-induced chlorophyll fluorescence ( $\left.\mathrm{F}_{760}\right)$ and heat dissipation can in principle be retrieved using hyperspectral optical data. The heat dissipation can be detected using the Photochemical Reflectance Index (PRI), originally proposed [10] to track changes in the de-epoxidation state of the xanthophyll cycle pigments, 
related to heat dissipation. PRI has been used to track photosynthesis changes caused by water stress conditions with varying degrees of success [11-14]. In particular, PRI has been shown to be able to track the evolution of maize water stress from the early phase when only the plant physiology is affected [12] to the later ones when also plant structure changes [11], showing higher potentiality than the traditional greenness indices that hardly detect early stress conditions. More recently, the estimation of sun-induced chlorophyll fluorescence in the far-red region (at $760 \mathrm{~nm}$ ) has been proven feasible from remote sensors, and fluorescence has been evaluated as a novel remote measure to detect plant physiological changes due to environmental constraints $[15,16]$.

In this study, we used thermal and optical remote sensing imagery collected from an airborne platform at three different times during the day (morning, midday and afternoon) to detect maize water stress. An airborne campaign was conducted with the visible and near infrared CASI 1500 (Itres Research Ltd.) and thermal AHS-160 (Sensytech Inc.) sensors over an experimental maize field treated with three different irrigation regimes. As far as the authors know, a comparison of the performances of different water stress indicators derived from both optical and thermal high resolution data during the day has not been fully explored yet. A better understanding of the performances of different remotely sensed water stress indicators is essential for farmers and service providers to support agricultural management.

The specific objectives were to: (i) determine the potential of using airborne optical and thermal image acquisitions to detect different levels of water deficit in a maize field; (ii) assess the performances of each radiometric quantity derived from the images analyzed separately; (iii) compare different vegetation indices, canopy temperature and CWSI to identify the best indicator of water stress at different times of the day and; (iv) the best time of the day for data collection and mapping.

\section{Materials and Methods}

\subsection{Experimental Area and Field Campaigns}

The study was conducted at the "Vittorio Tadini" experimental farm located in Northern Italy at latitude $44^{\circ} 58^{\prime} 49.00^{\prime \prime} \mathrm{N}$, longitude $9^{\circ} 40^{\prime} 48.50^{\prime \prime} \mathrm{E}$, elevation $87 \mathrm{~m}$ a.s.l. Maize plants were sown on June 3, 2010 over an area of about 1.2 ha. The field campaign was conducted between July 19 and 22, 2010 (between 46 and 49 days after sowing). Plants were in their pre-flowering stem elongation stage [17] with an average of 10 leaves emerged. This timing was selected for the survey because maize is more sensitive to water stress between the elongation and flowering stage [18].

Three water regimes were randomly assigned: rainfed, water deficit imposed between stem elongation and flowering and full irrigation (Irr0, Irr1 and Irr2, respectively). Water regimes were applied according to a split-plot experimental design with four blocks (Figure 1), being the water regime, the whole-plot treatment, crop species (maize and sorghum) and the split-plot treatment. Irrigation requirements were calculated from a daily soil water balance: Irr2 plots were supplied with the volume of water needed to bring Available Water Content (AWC) back to field capacity, whenever it dropped below 70\%; Irr 1 plots were supplied with the volume of water needed to keep AWC between $30 \%$ and $60 \%$. Each subplot was then divided into two more plots, $15 \times 16.5 \mathrm{~m}$ each, the first one not fertilized, the second one fertilized with $100 \mathrm{~kg} \cdot \mathrm{ha}^{-1}$ to enhance the variability of the biophysical parameters. The results shown 
in the study refer only to maize plots and include both nitrogen treatments. Further details about the study site are reported in Panigada et al. [11] and Cilia et al. [19].

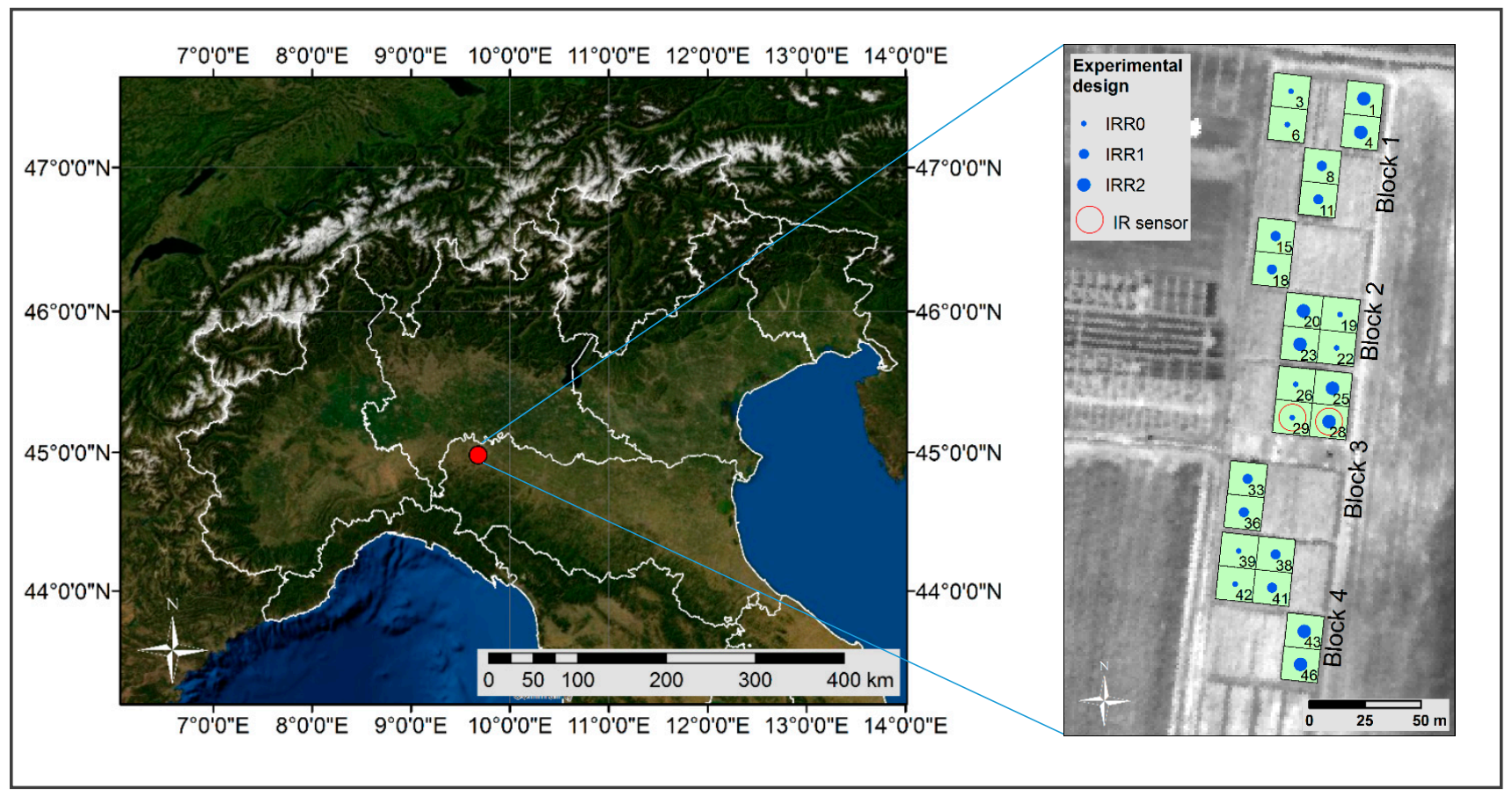

Figure 1. Experimental field location in Northern Italy and treatment scheme. The irrigation levels are shown as small circles in rainfed plots (Irr0), medium circles in water deficit plots (Irr1) and large circles in full irrigation plots (Irr2). Red circles indicate the position of the two infrared radiometer sensors in the maize field.

\subsection{Canopy Temperature}

Thermal data were taken continuously on two maize plots, a rainfed (Irr0, plot 29) and a fully irrigated (Irr2, plot 28) plot (Figure 1). The instruments used were two infrared radiometer sensors SI-111 (Apogee, UT, USA) with a $22^{\circ}$ half-angle field of view positioned $3 \mathrm{~m}$ above the ground with an inclination of $45^{\circ}$. These measurements were collected every $5 \mathrm{~min}$ and stored in a datalogger (model CR10X, Campbell Sci., Logan, UT, USA). The single-band infrared temperature sensors covered the range between 8 and $15 \mu \mathrm{m}$ with an accuracy of $\pm 0.2^{\circ} \mathrm{C}$. Air temperature (Ta) and relative humidity $(\mathrm{RH})$ were measured above the canopy with a portable weather station equipped with Vaisala sensors. The difference between crown and air temperature $(\Delta \mathrm{T})$ was calculated using temperature data measured at the same time. $\Delta \mathrm{T}$ was calculated because it provides the gradient for the flow of sensible heat toward or away from a vegetal surface, regulated by plant evapotranspiration [20]. Positive values of $\Delta \mathrm{T}$ correspond to flow of sensible heat away from the canopy, indicating a reduction of transpiration rates.

\subsection{Field Data}

Leaf measurements were collected between 11:00 and 12:30 UTC on July 19 and 20 on maize plots to track the effects of water stress on crop condition and functioning. Measurements were conducted on the youngest fully expanded leaf. 
The efficiency of light reactions of photosynthesis was measured on single leaves using the miniaturized Fluorescence Yield Analyser (Mini-PAM) (H. Walz, Effeltrich, Germany) with a leaf clip holder described in Bilger et al. [21]. Measurements were conducted on 45 plants per treatment (15 leaves from fifteen different plants in each plot, $n=360)$. The steady-state value of fluorescence $\left(\mathrm{F}_{\mathrm{t}}\right)$ was measured under incident photosynthetic photon flux density (PPFD) conditions and a saturating light pulse ( $800 \mathrm{~ms}$ duration, intensity $\sim 4000 \mu \mathrm{mol} \cdot \mathrm{m}^{-2} \cdot \mathrm{s}^{-1}$ ) was superimposed on the prevailing environmental light level to measure the maximum light adapted fluorescence yield $\left(\mathrm{F}_{\mathrm{m}}^{\prime}\right)$. The effective quantum yield of photosystem II $\left(\Delta \mathrm{F} / \mathrm{F}^{\prime} \mathrm{m}\right)$, reflecting the fraction of light utilized in photosystem II photochemistry at a given light intensity, was then calculated as $\left(\mathrm{F}_{m}^{\prime}-\mathrm{F}_{\mathrm{t}}\right) / \mathrm{F}^{\prime} \mathrm{m}$.

Leaf $\mathrm{CO}_{2}$ exchanges were measured with an open infrared gas exchange system (CIRAS-1, PP-Systems, Stotfold, UK). Measurements were performed at ambient $\mathrm{CO}_{2}$ concentrations and illumination using a Parkinson leaf chamber clamped to single leaves. Instantaneous net assimilation $\left(\mathrm{A}_{\mathrm{i}}\right)$ and stomatal conductance to water vapor $\left(\mathrm{G}_{\mathrm{i}}\right)$ were recorded simultaneously on three leaves from different plants from six plots (block 2).

The relative chlorophyll content (Chl) was measured with a SPAD 502 meter (Minolta, Tokyo, Japan) on 10 leaves from 10 different plants for each plot. The SPAD is a non-destructive, hand-held instrument that measures light attenuation at $650 \mathrm{~nm}$ (i.e., close to the maximum total chlorophyll absorption) and $950 \mathrm{~nm}$ from a $0.06 \mathrm{~cm}^{2}$ leaf area. Differences in light attenuation are converted in SPAD unit, proportional to leaf chlorophyll concentration.

Leaf samples for the estimation of water content were collected in the twelve fertilized plots (four leaves from different plants for each plot). The leaf equivalent water thickness (EWT) and the relative water content (RWC) were calculated according to the following equations:

$$
\begin{aligned}
& E W T=\frac{F W-D W}{A} \\
& R W C=\frac{F W-D W}{T W-D W}
\end{aligned}
$$

where FW is the fresh weight of leaf disks with an area (A) of $3.8 \mathrm{~cm}^{2}$; DW is the dry weight of the leaf disks dried at $80^{\circ} \mathrm{C}$ in an oven until constant weight; TW is the turgid weight measured on the leaf disks immersed for $72 \mathrm{~h}$ in distilled water, blotted and weighed.

Finally, the leaf area index (LAI, $\mathrm{m}^{2} \mathrm{~m}^{-2}$ ) and the photosynthetically active radiation absorbed by vegetation (APAR) were measured in each plot using a linear ceptometer in the PAR (Photosynthetically Active Radiation) domain (SunScan Canopy Analysis System, Delta-T devices, Burwell, UK). Measurements were conducted according to the SunScan user manual [22]: incident and reflected radiation was measured from about $0.5 \mathrm{~m}$ above the top of the canopy in each plot; the direct to diffuse radiation ratio was estimated by conducting a second incident radiation measurement after shadowing about $1 / 4$ of the probe sensors (100 cm long); seven readings of transmitted solar radiation at ground level were collected and averaged along a transect crossing two consecutive crop rows. LAI was then estimated exploiting the SunScan internal software. Leaf absorption in the PAR domain was assumed to be equal to 0.85 , while the ellipsoidal leaf angle distribution parameter was set to 1.37 [23]. The APAR was computed as:

$$
A P A R=P A R_{i}-P A R_{t}-P A R_{r}
$$


where PAR $\mathrm{R}_{\mathrm{i}}$ is the above-canopy incident PAR, PAR $\mathrm{t}$ and PAR $\mathrm{r}$ are the transmitted and reflected PAR, respectively.

\subsection{Airborne Hyperspectral Imagery Acquisition and Processing Techniques}

An airborne campaign was conducted by the Spanish Instituto Nacional de Técnica Aerospacial (INTA) on July 19. Images were acquired with a CASI 1500 (Itres Research Ltd.) and an AHS-160 (Sensytech Inc.) sensor. Three surveys were scheduled at 8:30, 11:30 and 14:30 UTC in order to characterize photoprotection, fluorescence and temperature differences related to plant water stress during the course of the day. The sensors onboard the same airplane were flown at a relative height of $1067 \mathrm{~m}$ to acquire AHS images with a $2.5 \mathrm{~m}$ pixel resolution and at $2013 \mathrm{~m}$ to acquire CASI images at $1 \mathrm{~m}$ pixel resolution. In Tables 1 and 2 the sensor and the acquired image characteristics are presented.

Table 1. Sensor characteristics and spectral region covered; FWHM is the full width at half maximum; IFOV is the instantaneous field of view.

\begin{tabular}{ccccc}
\hline Sensor & Spectral Range $(\mathbf{n m})$ & $\mathbf{N}^{\circ}$ of Bands & FWHM $(\mathbf{n m})$ & IFOV $(\mathbf{m r a d})$ \\
\hline CASI 1500 & $380-1050$ & 72 & $2.4-14.4$ & 0.5 \\
\hline AHS & $430-1030$ & 20 & 28 & \\
& $1550-1750$ & 1 & 200 & \\
& $2000-2560$ & 42 & 13 & 2.5 \\
& $3300-5400$ & 7 & 300 & \\
& $8200-12,700$ & 10 & 400 & \\
\hline
\end{tabular}

Table 2. Acquisition time (reported in UTC) and solar zenith angle $\left(\theta_{s}\right)$ for the different runs acquired in the solar principal plane.

\begin{tabular}{ccc}
\hline RUN & Time (UTC) & $\boldsymbol{\theta}_{\mathbf{s}}\left({ }^{\circ}\right)$ \\
\hline CASI \#1 & $08: 40$ & 42 \\
CASI \#4 & $11: 24$ & 24 \\
CASI \#5 & $14: 20$ & 43 \\
AHS \#1 & $08: 26$ & 45 \\
AHS \#2 & $11: 04$ & 25 \\
AHS\#3 & $14: 01$ & 40 \\
\hline
\end{tabular}

AHS thermal images were georeferenced using the PARGE ${ }^{\odot}$ software, with position and observation angle recorded by the GPS/IMU sensors installed onboard the aircraft.

AHS images were used to estimate the temperature of the vegetation component with the method proposed by Panigada et al. [11]. Briefly, the method describes the temperature of each pixel of the scene as a mix of soil and vegetation components characterized by homogeneous temperature based on the study of Gillespie [24].

Given this assumption, the radiance emitted from each AHS pixel at each wavelength $i$ can be written as:

$$
L_{g}\left(\lambda_{i}\right)=f c_{V} \cdot \varepsilon_{V}\left(\lambda_{i}\right) \cdot B\left(T_{C}, \lambda_{i}\right)+f c_{S} \cdot \varepsilon_{S}\left(\lambda_{i}\right) \cdot B\left(T_{S}, \lambda_{i}\right)+e\left(\lambda_{i}\right)
$$

where $f c_{V}$ and $f c_{S}$ are the fractions of vegetation and soil within the pixel, $\varepsilon_{V}\left(\lambda_{i}\right)$ and $\varepsilon_{S}\left(\lambda_{i}\right)$ are the emissivities of the vegetation canopy and soil components in each band $i$ (assumed constant for all 
pixels), $B\left(T_{C}, \lambda_{i}\right), B\left(T_{S}, \lambda_{i}\right)$ are the black body ground leaving radiances for vegetation canopy and soil, related to the skin temperature of the two components ( $T_{C}$ and $T_{S}$, respectively) and for the wavelength of the band $\lambda_{i}$ according to Planck's emission law and $e\left(\lambda_{i}\right)$ is the residual error term in each band $i$.

With $f c_{V}$ and $f c_{S}$ estimated from the visible and near infrared CASI data and $\varepsilon_{V}(\lambda)$ and $\varepsilon_{S}(\lambda)$ known, the system of Equation (4) for each band can be solved with respect to $T_{C}$ and $T_{S}$ using the Truncated Newtonian minimization algorithm (TNMIN-Markwardt IDL library), for each pixel of the experimental site.

Canopy temperature (Tc) and air temperature (Ta) were used to calculate the CWSI with Equation (5):

$$
C W S I=\frac{\left(T_{C}-T_{a}\right)-\left(T_{C}-T_{a}\right)_{L L}}{\left(T_{C}-T_{a}\right)_{U L}-\left(T_{C}-T_{a}\right)_{L L}}
$$

where $(\mathrm{Tc}-\mathrm{Ta})_{\mathrm{LL}}$ is the lower limit of the difference between canopy and air temperature and it corresponds to the $\Delta \mathrm{T}$ value of the "non-water-stressed baseline" for a given evaporative demand (potential crop). ( $\mathrm{Tc}-\mathrm{Ta}$ ) UL corresponds to the upper limit of the $\Delta \mathrm{T}$ value of a canopy where transpiration is completely halted (dry crop).

The lower and upper baselines were established using Tc measurements obtained from thermal images collected with a portable FLIR thermocamera (model i60, FLIR ${ }^{\circledR}$ Systems, Inc., Wilsonville, OR, USA) measuring in the range from $8-13.5 \mu \mathrm{m}$. Thermal images have been collected at regular time intervals between 10:30 and 14:30 UTC in the days close to the overpass on well watered maize plants (potential crop) and standing cut plants (dry crop). The difference between Tc values extracted only from the vegetated components of the collected images and corresponding Ta values measured by a portable weather station have been related to VPD to define the lower and upper baselines. $\Delta \mathrm{T}$ values are significantly linearly related to VPD in well watered plants $\left(\mathrm{R}^{2}=0.64, p<0.001\right)$ confirming that plants regulate their temperature in response to variation in the evaporative demand. On the contrary, the relation between $\triangle \mathrm{T}$ and VPD in dry plants is not significant and the UL baseline was calculated as the average $\Delta \mathrm{T}$ of dry plants as suggested in [25]. The resulting lower and upper baselines are reported in Equations (6) and (7), respectively.

$$
\begin{gathered}
T c-T a=4.04-2.10 \cdot V P D \\
T c-T a=4.67
\end{gathered}
$$

Coefficients of Equation (6) are close to those developed for maize and presented in $[5,26]$. The UL baseline value is similar to the average $\Delta \mathrm{T}_{\mathrm{UL}}$ of $4.6^{\circ} \mathrm{C}$, measured over a severely stressed maize plot under a Mediterranean semi-arid climate [27]. The calculation of CWSI was restricted to flights conducted at 11:04 and 14:01 UTC, coinciding with the times at which the baselines were originally obtained.

The CASI images were georeferenced using the geocor tool provided by Itres (Canada), based on the position and observation angle recorded by the GPS/IMU sensors installed onboard. They were atmospherically corrected with the empirical line method [28] based on an empirical relationship between at-sensor radiance and surface reflectance measured at the time of each overpass. This was recorded in the field on five different targets (white and black panels, two soils and asphalt) by means of a FieldSpec PRO spectroradiometer (Analytical Spectral Devices Inc., Boulder, CO, USA) ranging from $350-2500 \mathrm{~nm}$.

Several optical indices were calculated from mean reflectances (Table 3). 
Table 3. Vegetation indices tested in this study. $\mathrm{R}_{x}$ is the reflectance at the wavelength $x$ of the CASI band centers used for calculations expressed in $\mathrm{nm}$.

\begin{tabular}{ccc}
\hline Index & Formula & Reference \\
\hline NDVI & $\left(\mathrm{R}_{800}-\mathrm{R}_{680}\right) /\left(\mathrm{R}_{800}+\mathrm{R}_{680}\right)$ & {$[29]$} \\
OSAVI & $\left(\mathrm{R}_{800}-\mathrm{R}_{680}\right) /\left(\mathrm{R}_{800}+\mathrm{R}_{680}+0.16\right)$ & {$[30]$} \\
TCARI & $3 \times\left[\left(\mathrm{R}_{700}-\mathrm{R}_{670}\right)-0.2 \times\left(\mathrm{R}_{700}-\mathrm{R}_{550}\right) \times\left(\mathrm{R}_{700} / \mathrm{R}_{670}\right)\right]$ & {$[31]$} \\
TCARI/OSAVI & $\mathrm{TCARI} / \mathrm{OSAVI}$ & {$[31]$} \\
VARI & $\left(\mathrm{R}_{560}-\mathrm{R}_{670}\right) /\left(\mathrm{R}_{560}+\mathrm{R}_{670}-\mathrm{R}_{473}\right)$ & {$[32]$} \\
PRI & $\left(\mathrm{R}_{531}-\mathrm{R}_{570}\right) /\left(\mathrm{R}_{531}+\mathrm{R}_{570}\right)$ & {$[10]$} \\
\hline
\end{tabular}

Selected indices were the Normalized Difference Vegetation Index (NDVI) expected to track changes in LAI, biomass amount and canopy structure; the TCARI/OSAVI designed to be sensitive to chlorophyll content; the Visible Atmospherically Resistant Index (VARI) sensitive to vegetation fraction and minimally affected by changes in atmospheric properties and the Photochemical Reflectance Index (PRI), originally developed for the detection of changes in the xanthophyll epoxidation state.

Furthermore CASI at sensor radiances were used to estimate F760 using the method first proposed by Maier et al. [33] and then applied in different studies [11,34]. Top of canopy fluorescence was computed exploiting non fluorescent targets (white and black panels, low and high reflecting soils and asphalts) present in the scene to estimate the atmospheric transmittance and path radiance inside and outside the absorption feature.

The radiance emitted as fluorescence $\left(\mathrm{L}^{\mathrm{f}}\right)$ is estimated solving the following equation:

$$
k_{3} \cdot L^{f}=L_{i}-k_{1} \cdot L_{o}-k_{2} k_{1}
$$

where $L_{i}$ and $L_{o}$ are the radiances inside and outside the oxygen A absorption band;

$$
k_{3}=T_{i}-k_{1} \cdot T_{o} k_{2}=L_{i}^{\text {path }}-k_{1} \cdot L_{o}^{\text {path }}
$$

where $\mathrm{T}_{\mathrm{i}}$ and $L_{i}^{\text {path }}$ are the atmospheric transmittance and path radiance inside the absorption band and $\mathrm{T}_{\mathrm{o}}$ and $L_{o}^{\text {path }}$ the atmospheric transmittance and path radiance outside the absorption band;

$$
k_{1}=\left(\frac{T_{i} E_{i}}{T_{o} E_{o}}\right)
$$

with $\mathrm{E}_{\mathrm{i}}$ and $\mathrm{E}_{\mathrm{o}}$ the incident irradiance inside and outside the absorption band;

$$
k_{2}=L_{i}^{\text {path }}-k_{1} \cdot L_{o}^{\text {path }}
$$

One band inside (centered at $762.34 \mathrm{~nm}$ ) and two bands outside (centered at 755.2 and $757.5 \mathrm{~nm}$ ) the absorption band were used to compute $\mathrm{L}_{\mathrm{i}}$ and $\mathrm{L}_{\mathrm{o}}$, respectively. The apparent fluorescence yield (Fy*760) was also computed per each overpass as the ratio between $\mathrm{F}_{760}$ and the simultaneous incident photosynthetically active radiation measured with a portable weather station [35]. The fluorescence yield (Fy760) was computed for the second CASI flight as the ratio between $\mathrm{F}_{760}$ and the APAR measured with the linear ceptometer at the time of the second overpass. 


\subsection{Data Analysis}

The correlation ratio [36] was calculated to describe the effect of the irrigation treatment on the parameters measured in the field. The correlation ratio $\eta^{2}$ is defined as:

$$
\eta^{2}=\frac{\sigma_{\bar{y}}^{2}}{\sigma_{y}^{2}} \quad \text { where } \quad \sigma_{\bar{y}}^{2}=\frac{\sum_{x} n_{x}\left(\bar{y}_{x}-\bar{y}\right)^{2}}{\sum_{x} n_{x}} \quad \text { and } \quad \sigma_{y}^{2}=\frac{\sum_{x, i} n_{x}\left(y_{x i}-\bar{y}\right)^{2}}{n}
$$

where $\sigma$ is the standard deviation, $\mathrm{y}_{\mathrm{xi}}$ represents each observation with $\mathrm{x}$ the factor irrigation and $\mathrm{i}$ the number of the considered observation, $\mathrm{n}_{\mathrm{x}}$ is the number of observations in category $\mathrm{x}, \bar{y}_{x}$ is the mean of the category $\mathrm{x}$ and $\bar{y}$ is the mean of the whole population. The correlation ratio can assume values between 0 and 1 and gives an indication of how much the data variance is explained by the factor irrigation. A high correlation ratio (close to 1) means that the factor irrigation explains all the data variance.

The relationships between field measurements and vegetation indices have been assessed extracting mean reflectance spectra from an area centered in each of the 24 maize plots $(3 \times 3$ pixels for AHS and $9 \times 9$ pixels for CASI corresponding to $56 \mathrm{~m}^{2}$ and $81 \mathrm{~m}^{2}$, respectively). The analysis of the sensitivity of different indices to the applied water regimes has been conducted extracting mean spectral data from the same areas. The effect of the irrigation treatment on the radiometric quantities investigated in this study was tested with the non-parametric Kruskal-Wallis test.

\section{Results and Discussion}

\subsection{Field Data}

The deficit irrigation regimes applied in this experiment caused a general decrease of different leaf parameters as compared to the full irrigation regime. The percentage variation of each parameter compared to the value measured in the Irr 2 plots is reported in Table 4 together with the correlation ratio describing the effect of the irrigation treatment on the measured parameters.

The $\mathrm{CO}_{2}$ instantaneous assimilation $\left(\mathrm{A}_{\mathrm{i}}\right)$ and instantaneous stomatal conductance $\left(\mathrm{G}_{\mathrm{i}}\right)$ were the parameters most affected by water regimes, with a decrease in Irr0 plots greater than $20 \%$ compared to Irr2 plots. This is not surprising because stomatal conductance is one of the most reliable indicators of water stress as water stress induces stomatal closure to reduce the transpiration rate and therefore the $\mathrm{CO}_{2}$ assimilation rate. $\Delta \mathrm{F} / \mathrm{Fm}_{\mathrm{m}}$ showed a decrease of $15 \%$ in Irr0 plots, while leaf biochemical parameters (Chl, EWT and RWC) showed a reduced variation caused by water regimes with a maximum decline of $6 \%$. Plants reacted to water stress also by reducing LAI. In fact, a reduction of $20.7 \%$ was observed from Irr2 to Irr 1 and a reduction of $31 \%$ from Irr2 to Irr0. However, LAI measurements were characterized by a higher within-treatment variability (coefficient of variation of $17 \%, 30 \%$ and $35 \%$ for Irr2, Irr 1 and Irr0 plots, respectively) compared to leaf measurements, lowering the amount of LAI variance explained by the factor irrigation $\left(\eta^{2}=0.42\right)$. It is interesting to note that the coefficient of variation of LAI within treatments increased as the water stress increased. 
Table 4. Descriptive statistics (i.e., mean and standard deviation (SD)) of maize leaf parameters grouped per irrigation treatment. Photosynthetic efficiency $(\Delta \mathrm{F} / \mathrm{Fm})$, stomatal conductance to water vapour $\left(\mathrm{G}_{\mathrm{i}}\right)\left(\mathrm{mmol} \mathrm{H} \mathrm{O} \mathrm{m}^{-2} \cdot \mathrm{s}^{-1}\right)$, instantaneous assimilation $\left(\mathrm{A}_{\mathrm{i}}\right)(\mu \mathrm{mol}$ $\mathrm{CO}_{2} \mathrm{~m}^{-2} \cdot \mathrm{s}^{-1}$ ), relative chlorophyll content $(\mathrm{Chl})$, equivalent water thickness (EWT, $\mathrm{cm}$ ) and relative water content $(\mathrm{RWC}, \%)$. The correlation ratio $\eta^{2}$ describing the effect of the irrigation treatment on the parameters is also reported. It is not available (n. a.) for $A_{i}$ and $G_{i}$ due to the small sample number.

\begin{tabular}{ccccccc}
\hline Parameter & Irr2 & \multicolumn{2}{c}{ Irr1 } & \multicolumn{2}{c}{ Irr0 } & $\boldsymbol{\eta}^{2}$ \\
\hline & & Mean \pm SD & $\begin{array}{c}\text { \% Decrease } \\
\text { Compared to Irr2 }\end{array}$ & Mean \pm SD & $\begin{array}{c}\text { \% Decrease } \\
\text { Compared to Irr2 }\end{array}$ \\
\hline$\Delta \mathrm{F} / \mathrm{F}_{\mathrm{m}}{ }^{\prime}$ & $0.39 \pm 0.01$ & $0.36 \pm 0.03$ & -7.7 & $0.33 \pm 0.03$ & -15 & 0.52 \\
$\mathrm{G}_{\mathrm{i}}$ & $254 \pm 60$ & $207 \pm 20$ & -18.5 & $200 \pm 30$ & -21.3 & n. a. \\
$\mathrm{A}_{\mathrm{i}}$ & $42.43 \pm 3.42$ & $36.87 \pm 3.42$ & -13.1 & $32 \pm 1.65$ & -24.6 & n. a. \\
$\mathrm{Ch} 1$ & $52.8 \pm 4.0$ & $49.8 \pm 4.9$ & -5.7 & $49.9 \pm 2.9$ & -5.5 & 0.12 \\
$\mathrm{EWT}$ & $0.0135 \pm 0.0006$ & $0.0130 \pm 0.0004$ & -3.7 & $0.0127 \pm 0.0005$ & -5.9 & 0.33 \\
$\mathrm{RWC}$ & $95.4 \pm 0.5$ & $92.5 \pm 0.9$ & -3 & $93.1 \pm 1.9$ & -2.4 & 0.57 \\
\hline
\end{tabular}

\subsection{Thermal Data}

The diurnal courses of $\Delta \mathrm{T}$ continuously monitored on the day of the airborne overpasses are shown in Figure 2.
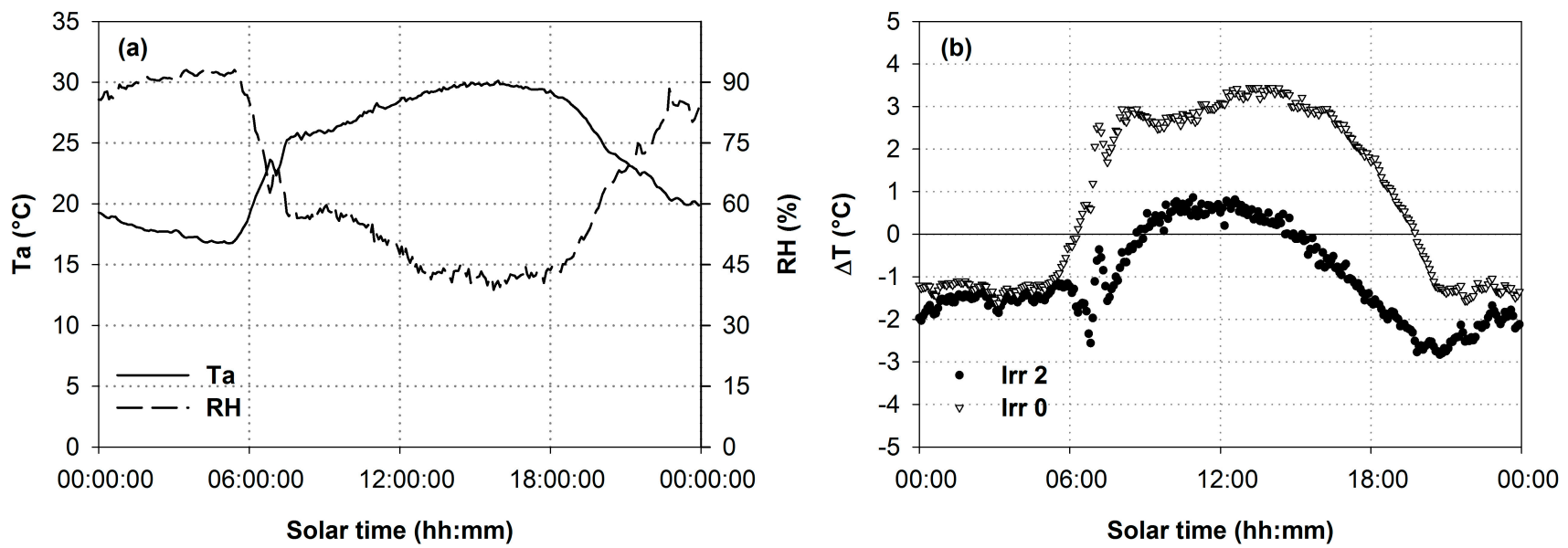

Figure 2. Diurnal course of air temperature $\left(\mathrm{Ta},{ }^{\circ} \mathrm{C}\right)$, relative humidity $(\mathrm{RH}, \%)(\mathbf{a})$ and difference between canopy and air temperature $\left(\Delta \mathrm{T},{ }^{\circ} \mathrm{C}\right)(\mathbf{b})$ for the two plots (one Irr0 and one Irr2) continuously monitored on the day of the airborne overpasses.

$\Delta \mathrm{T}$ was similar for the Irr0 and Irr2 plots during nighttime but it strongly differed during daylight hours in terms of both absolute values and shape. Plot Irr0 showed higher values of $\Delta \mathrm{T}$ compared to plot Irr2 and $\Delta \mathrm{T}$ rise was very steep in the morning, then it kept positive values of about $3{ }^{\circ} \mathrm{C}$ for the majority of the day and finally started to decrease in the mid-afternoon following the decrease in $\mathrm{T}$ air. On the contrary, $\Delta \mathrm{T}$ measured on the Irr 2 plot showed positive values only for about six hours during the day, from 9:00-15:00 local solar time. Furthermore, the maximum $\Delta \mathrm{T}$ value $\left(0.9^{\circ} \mathrm{C}\right)$ was considerably lower 
than the maximum value recorded in the Irr0 plot. In the first part of the morning and late afternoon, fully irrigated maize plants had lower Tc than Ta due to the cooling effect of transpiration.

The difference between canopy and air temperature is a reliable indicator of water status [7] and the observed $\Delta \mathrm{T}$ difference between the two plots can be attributed to restricted transpiration due to water limitation in Irr0 causing an increase in canopy temperature. The relationship between plant water stress and Tc is well known, due to the fact that water deficit induces a decrease of leaf stomatal conductance, as observed in Table 4, with a consequent reduction of the evapo-transpiration rate and an increase of leaf/canopy temperature [37]. The close link between $\Delta \mathrm{T}$ and stomatal conductance is confirmed by the significant relationship between the average $\Delta \mathrm{T}$ values extracted from the AHS map and field measurements of $\mathrm{G}_{\mathrm{i}}$ collected simultaneously to the midday airborne overpass $\left(\mathrm{R}^{2}=0.58\right.$, $p<0.05, n=6$ ) (Figure 3a). $\Delta \mathrm{T}$ showed the best fitting with $\Delta \mathrm{F} / \mathrm{Fm}^{\prime}\left(\mathrm{R}^{2}=0.66, p<0.001, n=24\right)$ (Figure $3 \mathrm{~b}$ ). $\Delta \mathrm{F} / \mathrm{F}_{\mathrm{m}}$ ' is related to plant photosynthetic efficiency and it has been often used as indicator of plant status. In this study, $\Delta \mathrm{F} / \mathrm{F}_{\mathrm{m}}$ ' is highly correlated with $\mathrm{G}_{\mathrm{i}}(r=0.96)$ thus can be regarded as an indicator of leaf photosynthetic efficiency due to water stress comparable to $\mathrm{G}_{\mathrm{i}}$. However, we are aware of the fact that for a wider range of values, the relationship between $\Delta \mathrm{F} / \mathrm{F}_{\mathrm{m}}$ and $\mathrm{G}_{\mathrm{i}}$ would not be linear, compromising the possibility to use $\Delta \mathrm{F} / \mathrm{F}_{\mathrm{m}}$ ' as indicator of water stress. A strong relationship between $\Delta \mathrm{T}$ and leaf EWT was also observed $\left(\mathrm{R}^{2}=0.52, p<0.01, n=12\right)$.
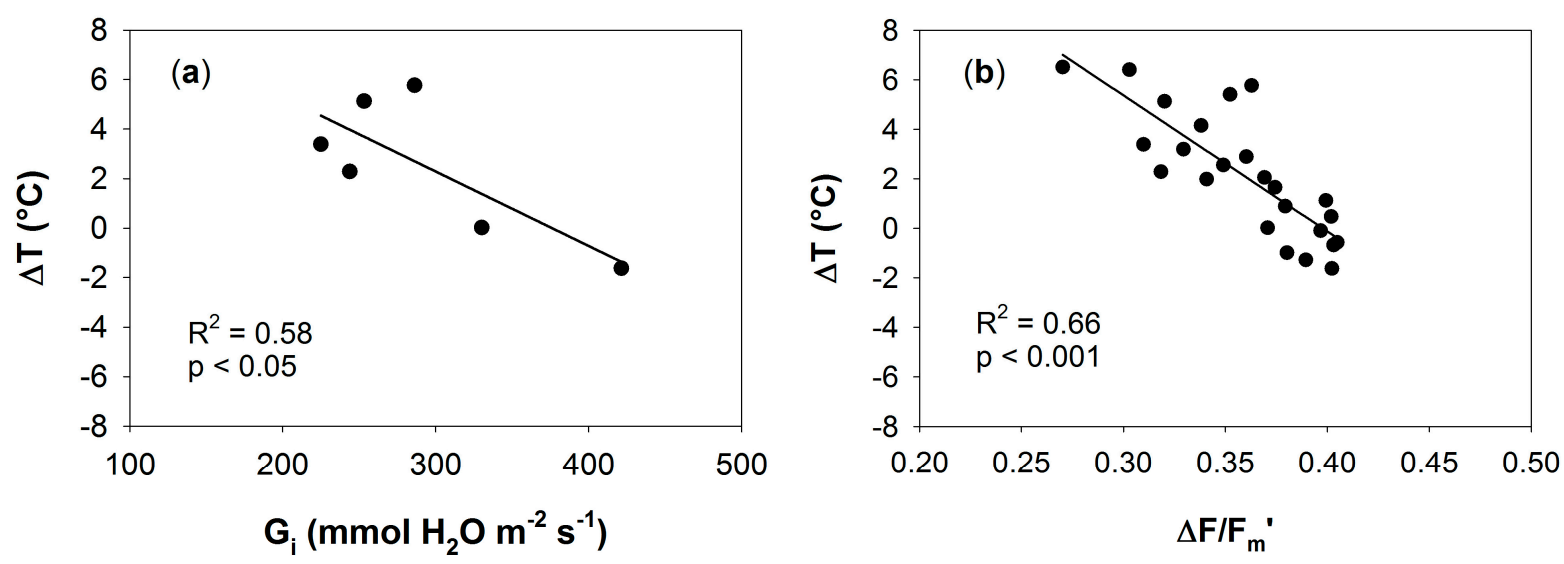

Figure 3. Relationship between image-based $\Delta \mathrm{T}$ and ground measured instantaneous

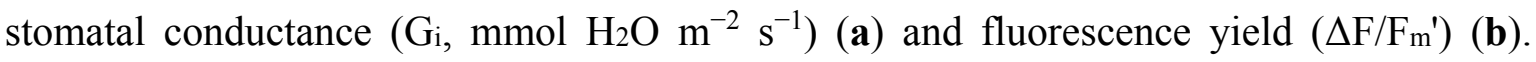
The determination coefficients and $p$ values of the linear regressions are reported.

Maps of Tc computed for each overpass over the 24 maize plots are shown in Figure 4.

Maximum canopy temperatures corresponded to rainfed plots reaching values of $40{ }^{\circ} \mathrm{C}$ at midday. The temperature of the stressed canopies was greater than Ta by a maximum difference of about $11^{\circ} \mathrm{C}$. Well-watered plots had lower Tc than Ta, particularly during the afternoon, due to the cooling effect of transpiration.

The accuracy of the maps has been evaluated comparing the average Tc value measured on ground at the time of the three overpasses with the average value extracted from the airborne Tc maps for each of the two plots and time of the day. The two Tc estimates agreed well $\left(\mathrm{R}^{2}=0.88, p<0.001\right)$ (Figure 5). Tc estimated from the airborne sensor are slightly lower than those measured on ground and the underestimation tends to increase with Tc (slope of the regression line equal to 0.88). Differences can 
be partly due to different viewing geometries, with ground measurements observing the crop with a view angle of $45^{\circ}$ and airborne instrument observing it from nadir.
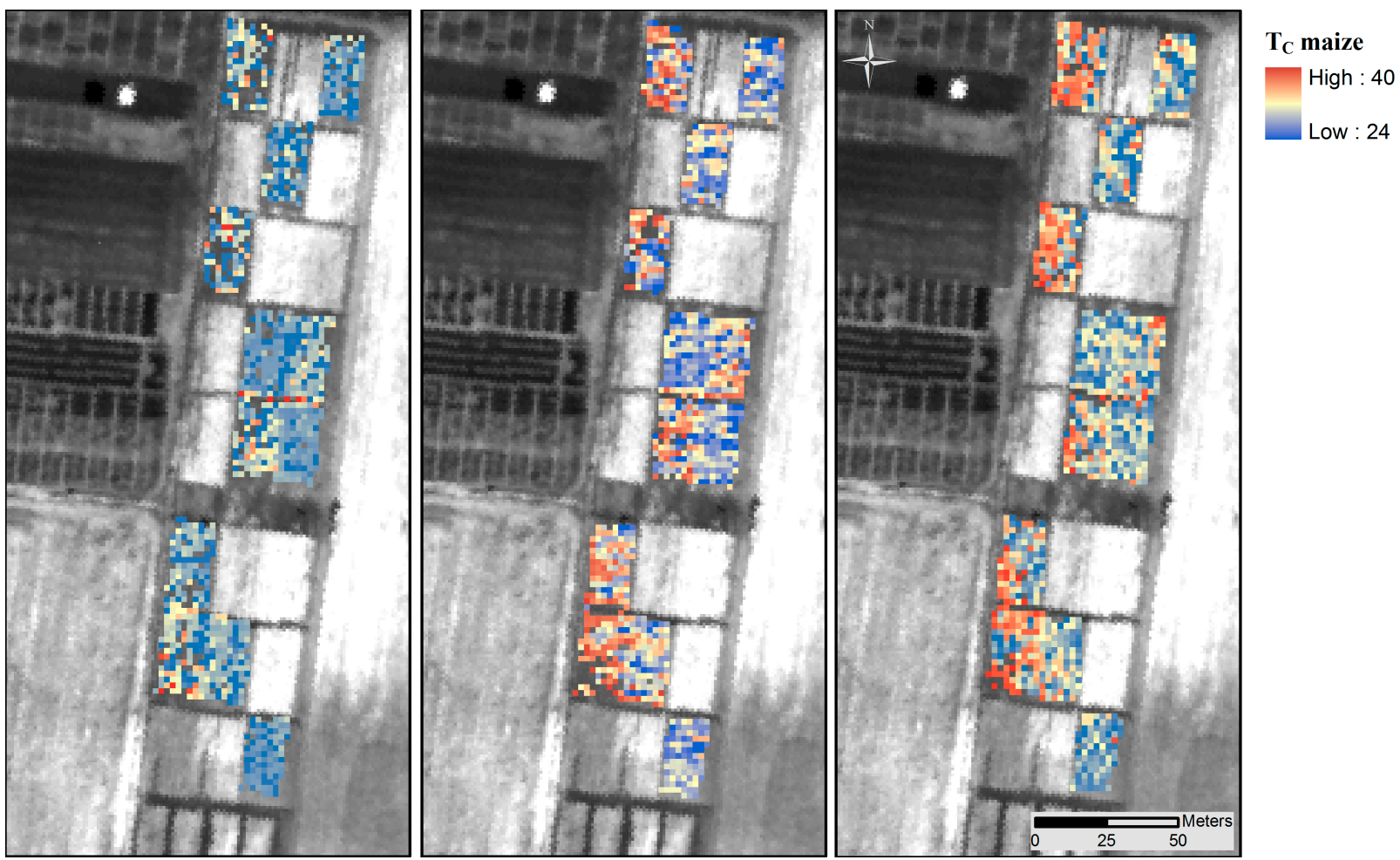

Figure 4. Maps of canopy temperature in maize plots during the morning (left), at midday (center) and during the afternoon (right). The corresponding Ta at the time of the overpasses were $26.2,28.6$ and $29.9^{\circ} \mathrm{C}$, respectively.

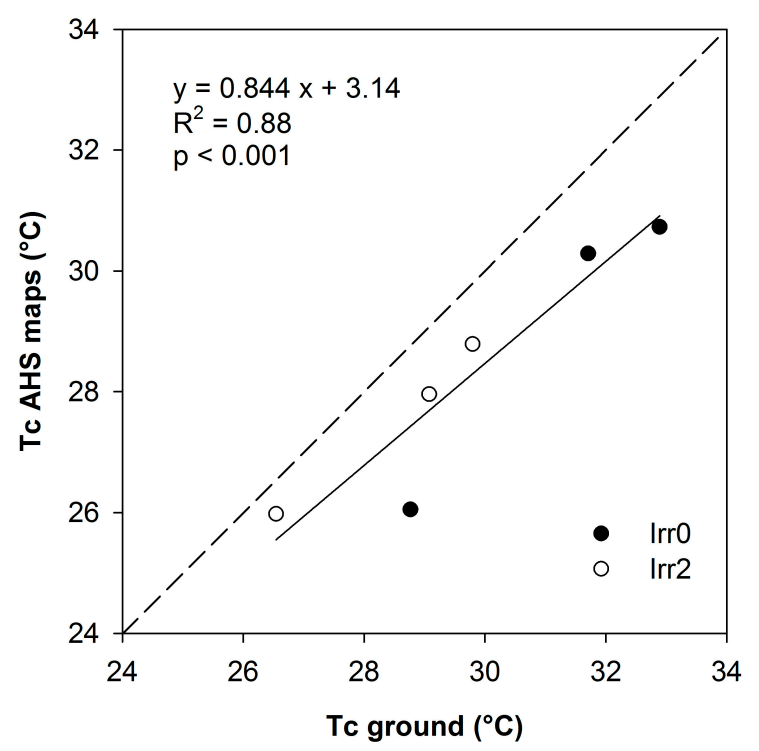

Figure 5. Relationship between the average $\mathrm{Tc}\left({ }^{\circ} \mathrm{C}\right)$ values measured on ground at the time of the three overpasses and the average value extracted from the airborne Tc maps for each of the two plots continuously monitored. 
The diurnal courses of $\mathrm{Tc}$ and $\Delta \mathrm{T}$ of the three water treatments (average of four plots each) derived from the AHS images (Figure 6) are similar to those observed on the ground (Figure 2). Mean plot temperatures from airborne thermal images varied in agreement with water regime with the mean temperature of the rainfed plots being from $3{ }^{\circ} \mathrm{C}-4.7{ }^{\circ} \mathrm{C}$ warmer than the irrigated treatment Irr 2 in the morning and at midday, respectively.

The difference between water treatments was maximized at midday with all three treatments being statistically different according to the Kruskal-Wallis test. On the contrary, the intermediate treatment Irr1 was not distinguishable from the other two during the morning and afternoon overflights. Even though $\mathrm{Tc}$ and $\Delta \mathrm{T}$ have been considered reliable indicators of water stress starting from 1970-1980 [7], changes in Tc during the day only recently have been proposed as an indicator [38]. The change between the morning and midday $T c$ was found here to correlate with $G_{i}$ with an $R^{2}$ of 0.65 , while the change between midday and afternoon Tc yielded to a weaker relation $\left(\mathrm{R}^{2}=0.22, n=6\right)$. Thus, careful planning of the time of acquisition of thermal images is essential when the slope of Tc as a function of time is used as a stress indicator. Promising results using images collected between 9:00 and 13:00 have been obtained as well in three Prunus species [38]. More studies are needed to evaluate the best suited time intervals for the slope calculation and to assess the robustness of the approach.
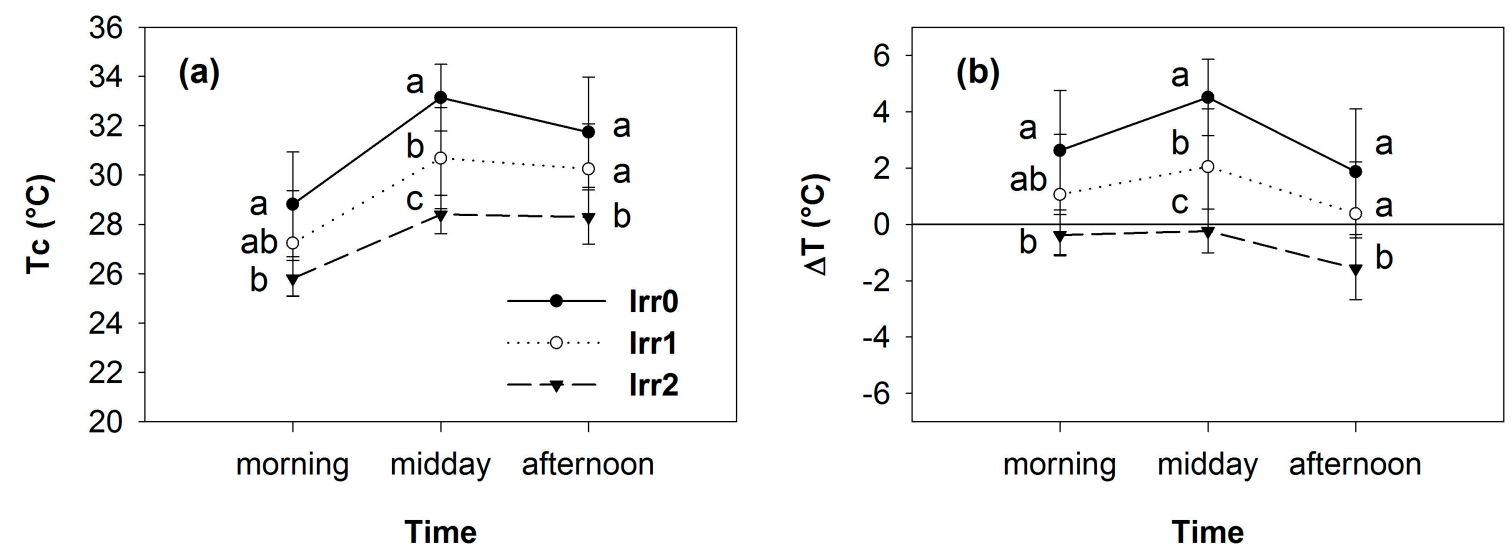

Figure 6. Time courses of average $\mathrm{Tc}\left({ }^{\circ} \mathrm{C}\right)(\mathbf{a})$ and $\Delta \mathrm{T}$ (b) for the three water treatments. Vertical bars are \pm one standard deviation. Tc and $\Delta \mathrm{T}$ were analyzed with the non-parametric Kruskal-Wallis test. The results of the test are evidenced by letters on the plots. Statistically different $(p<0.05)$ medians are designated with different letters.

Finally, the CWSI was computed based on the $\Delta \mathrm{T}$ maps acquired around midday and in the afternoon using the lower and upper limits of the relationships between $\Delta \mathrm{T}$ and VPD shown in Figure $7 \mathrm{a}$. CWSI is able to detect a significant difference between well irrigated and severely stressed plots in both the midday and afternoon flights (Figure 7b). Considering the midday flight, the average CWSI value ranged from 1 in Irr0 plots to a value close to 0 in Irr2 plots. During the afternoon, the average CWSI value decreased in the three treatments indicating that maize plants are better able to adjust the evaporative cooling in response to increased VPD. 

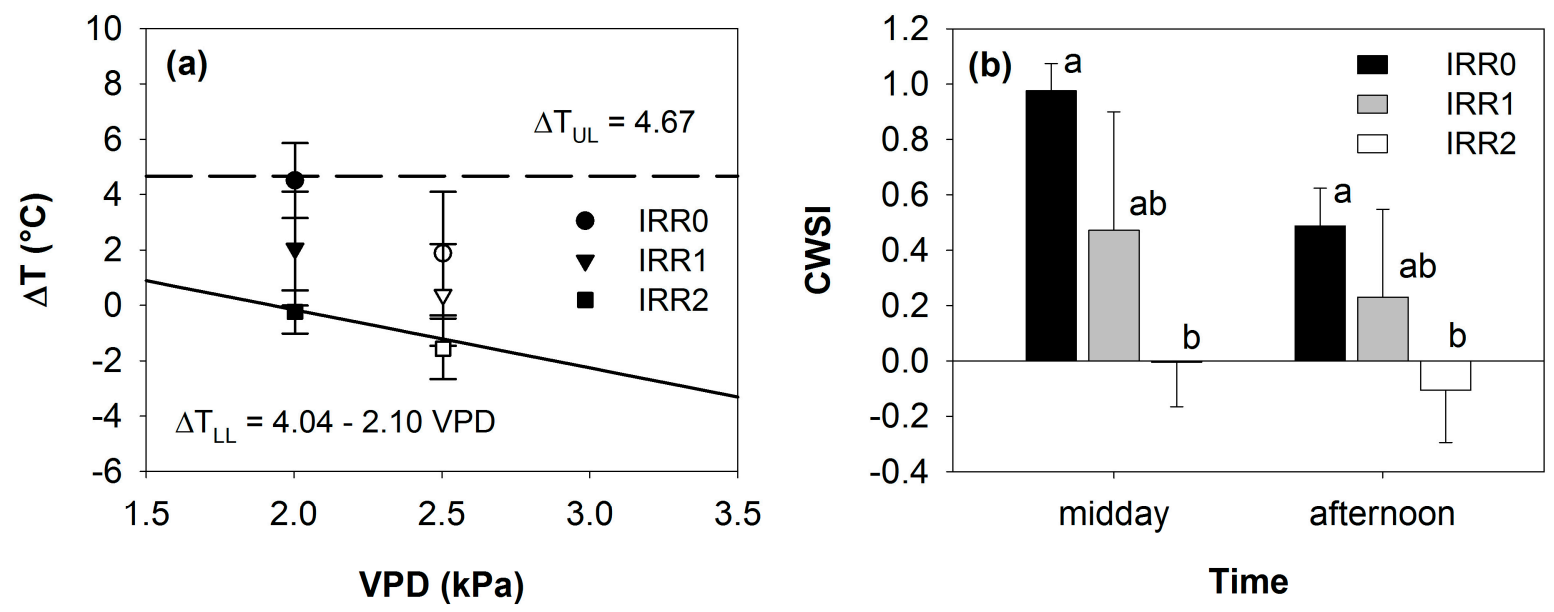

Figure 7. Lower and upper limits of the relationships between $\triangle \mathrm{T}$ and VPD for the determination of the crop water stress index (CWSI) in maize (a); average and standard deviation of the CWSI computed on the plots treated with three different water regimes on the midday and afternoon flights (b). CWSI analyzed with the non-parametric Kruskal-Wallis test. The results of the test are evidenced by letters on the plots. Statistically different $(p<0.05)$ medians are designated with different letters.

\subsection{Relationships between Optical Indices and Fluorescence and Field Parameters Measured at Midday}

The performances of the relationships between optical hyperspectral indices and passive fluorescence F760 derived from the second CASI flight and field parameters collected between 11:00 and 12:30 UTC have been evaluated.

NDVI was the index best related to LAI $\left(\mathrm{R}^{2}=0.63, p<0.001, n=24\right)$ and TCARI/OSAVI to leaf Chl content $\left(\mathrm{R}^{2}=0.65, p<0.001, n=24\right)$ confirming previous results [11] obtained on the same study site using the AISA Eagle hyperspectral airborne sensor (Specim, Finland).

PRI and $\mathrm{F}_{760}$ were significantly related to leaf $\Delta \mathrm{F} / \mathrm{F}_{\mathrm{m}}{ }^{\prime}$ measurements $\left(\mathrm{R}^{2}=0.46, p<0.001\right.$ and $\mathrm{R}^{2}=0.39$, $p=0.004, n=24$, for PRI and $\mathrm{F}_{760}$, respectively), while the relationship with $\mathrm{G}_{\mathrm{i}}$ was significant only with PRI $\left(\mathrm{R}^{2}=0.65, p=0.05, n=6\right)$. Interestingly, the relationships between $\Delta \mathrm{F} / \mathrm{F}_{\mathrm{m}}$ and $\mathrm{G}_{\mathrm{i}}$ and $\mathrm{Fy} 760$ are both significant and with higher determination coefficients compared to those between $\Delta \mathrm{F} / \mathrm{F}_{\mathrm{m}}$ and $\mathrm{G}_{\mathrm{i}}$ and $\mathrm{F}_{760}\left(\mathrm{R}^{2}=0.44, p<0.001\right.$ and $\mathrm{R}^{2}=0.51, p=0.11$ for $\Delta \mathrm{F} / \mathrm{F}_{\mathrm{m}}$ ' and $\mathrm{G}_{\mathrm{i}}$, respectively). It is worth noting that while $\mathrm{F}_{760}$ was positively related to $\Delta \mathrm{F} / \mathrm{F}_{\mathrm{m}}$, the sign of the relationship changes when we normalize F $760_{6 y}$ bPAR (Fy760). This means that stressed plants emitted more fluorescence per unit of absorbed PAR radiation. Further studies are needed to confirm this observation for different species, phenological stages and experimental conditions and to assess the best quantities to be used to normalize the $\mathrm{F}_{760}$ signal and make the use of $\mathrm{F}_{760}$ as a stress indicator easier.

\subsection{Diurnal Variations of Optical Indices and Fluorescence}

The temporal variations of different indices grouped by water treatment are shown in Figure 8 .

Whereas none of the investigated indices was able to statistically distinguish all three water treatments, all the indices except TCARI/OSAVI allowed the separation of the well irrigated plots (Irr2) and those more severely affected by water stress (Irr0). VARI is the only index able to detect a significant 
difference between moderate and severe water stress (Irr1 and Irr0 plots) in the midday flight, confirming some potential of this index to track water stress as already shown in previous studies $[39,40]$.

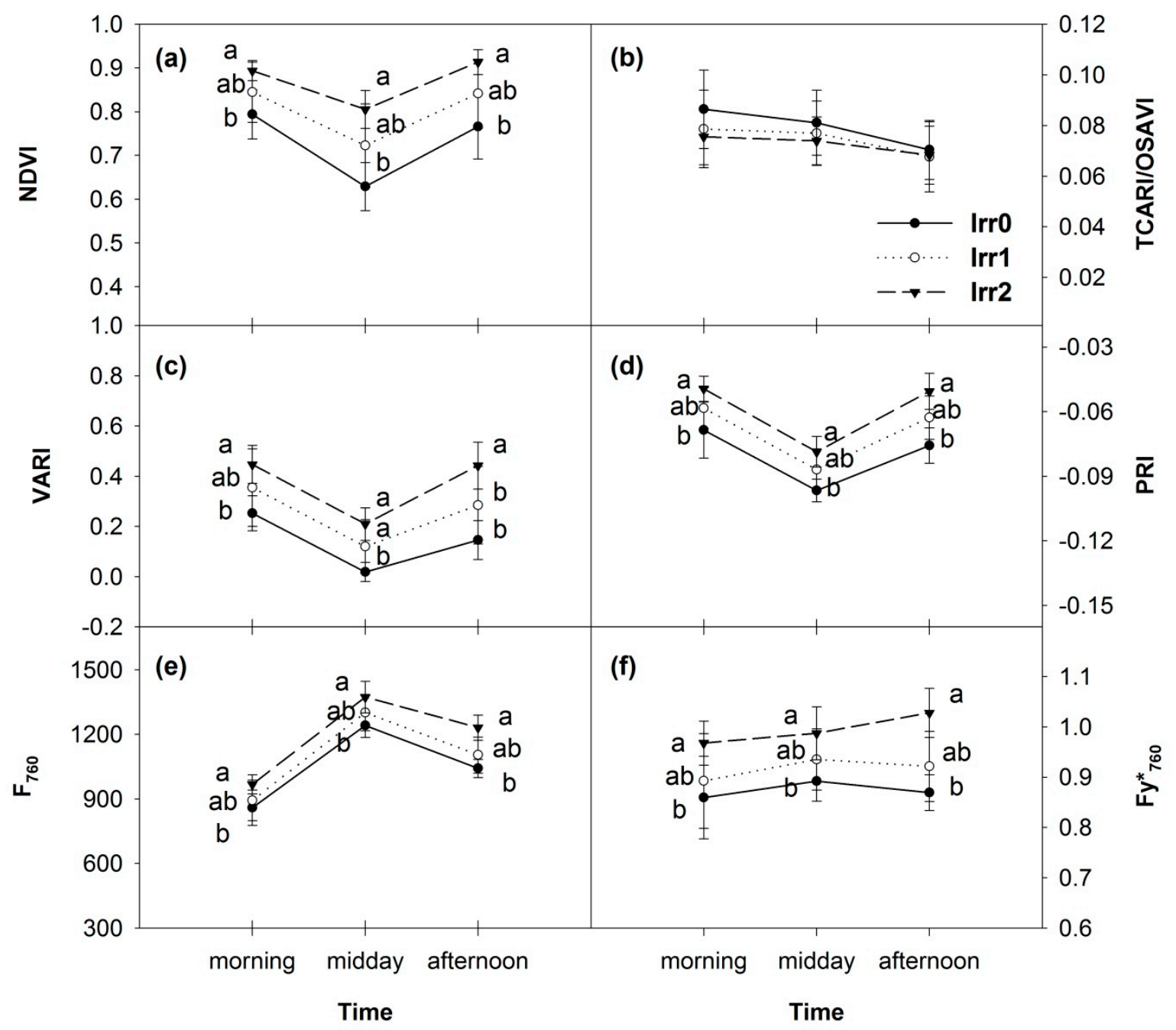

Figure 8. Time courses of NDVI (a); TCARI/OSAVI (b); VARI (c); PRI (d); F760 (e) and $\mathrm{Fy}^{*} 760$ (f) for the three water treatments. Vertical bars are \pm one standard deviation. Vegetation indices and fluorescence were analyzed with the non-parametric Kruskal-Wallis test. The results of the test are evidenced by letters on the plots. Statistically different $(p<0.05)$ means are designated with different letters.

NDVI showed a diurnal course with minimum values at midday and comparable values in the morning and afternoon. Irr2 plots had always higher NDVI values followed by Irr1 and Irr0 plots. Only Irr0 and Irr2 plots were statistically different. NDVI diurnal course is similar between the three treatments and can be explained by variations in the sun-target-sensor geometry during the day affecting the bidirectional reflectance distribution function (BRDF) and by the canopy elements in the sensor field of view. TCARI/OSAVI related to $\mathrm{Chl}$ content showed a reduced variability between treatments (differences not statistically significant) and also an almost absent diurnal shape. The weak relationship between TCARI/OSAVI and water stress is in agreement with results of the field data analysis showing that plants reacted to water stress by reducing LAI rather than Chl that was in fact weakly affected by the irrigation level (maximum reduction of 5.7\% compared to Irr2 plots). This can be explained 
considering that leaf elongation is among the plant processes most sensitive to water shortage [41]. Water deficit induces a reduction of plant growth rate, and consequently LAI, before triggering the degradation of leaf pigments. VARI showed a behavior similar to that of NDVI. The main differences are that VARI enhanced differences between Irr0 plots and the other two groups at midday and differences between Irr2 and the other two groups during the afternoon.

The diurnal changes of PRI are expected to be affected by both BRDF and absorption changes due to xanthophyll pigments depoxidation caused by diurnal water stress changes. Even if previous studies have demonstrated that the PRI index is sensitive to water stress levels, they also report that it is affected by the confounding effects of absorption of photosynthetic pigments, canopy structure, and background $[12,42,43]$.

F760 showed a diurnal trend mirroring the one of the incident photosynthetically photon flux density with higher values in Irr2 plots followed by Irr1 and then Irr0 plots. On the contrary, Fy* 760 shows a more stable daily course (Figure 8f) with the lowest values observed in Irr0 and the highest in Irr2 plots. This confirmed results obtained in previous studies where the $\mathrm{F}_{760}$ was lowered in plots with deficient water supply [11]. Again, only Irr0 and Irr2 plots were statistically different in terms of both F $_{760}$ and Fy* $^{*} 760$. However, the spectral resolution of the CASI sensor is not optimal for the estimation of $\mathrm{F}_{760}$ and we cannot exclude that the lower performances of $\mathrm{F}_{760}$ in stress detection compared to Tc could be partially explained by $\mathrm{F}_{760}$ estimations not accurate enough. A new airborne sensor specifically intended for sun-induced chlorophyll fluorescence estimation has been recently developed by the Forschungszentrum Jülich (Germany) in cooperation with the Finnish company Specim [44] and will open the possibility to fully verify the potential of fluorescence for stress detection with the best currently available spectral and radiometric resolution in the red and far-red regions.

\subsection{Synthesis of Thermal and Optical Data}

Results obtained from both the AHS and CASI images at different times of the day have been summarized in Table 5 where the indices previously analyzed separately have been listed according to their non-parametric Kruskal-Wallis statistic. Indices listed first are those showing variations attributed to water stress the most. NDVI performs better in discriminating different water stress levels during the morning flight. We propose the following explanation for this finding. NDVI has been shown to be sensitive to LAI; thus, the highest ranking observed during the morning can be attributed to differences in LAI values between plots irrigated with different water regimes. Structural LAI differences are the most evident during the morning because plants have not yet completely activated the dynamic mechanisms to cope with water stress. Thus, differences in biophysical and structural characteristics of the maize canopy due to the long term stress imposed have the strongest influence on the measured signal. As the day progresses, differences due to the regulation of evapotranspiration driven by water availability become predominant and $\Delta \mathrm{T}$ performs better in discriminating different water levels. This reasoning is corroborated by the fact that the performance of NDVI is not lowered dramatically during the day, while the performance of other indicators ( $\Delta \mathrm{T}$ at noon, PRI in the afternoon) that is improved with respect to the morning overpass. During the afternoon, irrigated plants may have reduced their regulation capacity through evapotranspiration due to high $\mathrm{Ta}$ and potential limitations in water 
availability typical of a full, sunny day. At this time, PRI and $F_{760}$ are the parameters differing the most among treatments.

Table 5. Ranking of different indices derived from both the AHS and CASI indices for the three overpasses based on the non-parametric Kruskal-Wallis test. The value of the Kruskal-Wallis statistic is reported within brackets.

\begin{tabular}{ccc}
\hline Morning & Midday & Afternoon \\
\hline NDVI $(11.045)$ & Tc and $\Delta \mathrm{T}(14.060)$ & PRI $(13.815)$ \\
PRI $(10.085)$ & NDVI $(13.265)$ & F $_{760}$ and Fy* ${ }_{760}(13.715)$ \\
Tc and $\Delta \mathrm{T}(9.465)$ & VARI $(12.285)$ & VARI $(12.635)$ \\
VARI $(9.26)$ & PRI $(11.535)$ & NDVI $(12.065)$ \\
F $_{760}$ and Fy* $*_{760}(7.22)$ & F $_{760}$ and Fy*760 $(9.465)$ & Tc and $\Delta \mathrm{T}(10.205)$ \\
TCARI/OSAVI $(2.195)$ & TCARI/OSAVI $(1.34)$ & TCARI/OSAVI $(0.32)$ \\
\hline
\end{tabular}

The ranking of best performing indices can be used to empirically identify the most suitable time interval for obtaining airborne images to be used to monitor crop water status. The optimum time to acquire thermal images is around noon, confirming previous results obtained by Bellvert et al. [45] in vineyards. Better performances of $\Delta \mathrm{T}$ around noon can be also partially explained considering that in the morning and afternoon images, the mutual shading of leaves increases causing different degrees of stomatal conductance within the canopy and lowering the relationship between $\Delta \mathrm{T}$ and water stress. NDVI performed evenly during the course of the day. This is because it tracked variations induced by water stress on canopy structure and green biomass that are expected not to vary during the course of one day. However, NDVI is expected to work only when the stress induces a variation in canopy biomass and structure. In a previous study by the authors [12], NDVI was not able to detect a moderate water stress condition, affecting the plant physiological status but not the canopy structure. PRI and fluorescence appears to be more discriminant in the afternoon overpass.

We cannot exclude though, a superimposed effect of changing illumination geometry during the day, not easily quantified, which could partially explain the changes in the relative performances of optical indices, fluorescence and temperature observed during the day.

\section{Conclusions}

With increasing water scarcity in many areas of the world, suitable indicators of crop water status are becoming more and more relevant to assist in precision irrigation management. In this study, airborne remote sensing data acquired with the hyperspectral CASI and AHS sensors were used to detect water stress in maize at three different levels of irrigation.

Field data showed that at the time of the overpasses maize plants were experiencing a mild to severe water stress in rainfed plots and a weaker stress condition in the plots with water deficit imposed between stem elongation and flowering. The performances of different vegetation indices, $\mathrm{F}_{760}$ and $\Delta \mathrm{T}$ in water stress detection were evaluated using three airborne overpasses conducted in the morning, midday and afternoon.

The study demonstrated the feasibility of using high resolution optical and thermal images to detect conditions of water deficit in a maize field. The optimum time to differentiate different water stress 
conditions was around noon using thermal images. PRI and $\mathrm{F}_{760}\left(\mathrm{Fy}^{*}{ }_{760}\right)$ showed the best performances in the afternoon. NDVI performed evenly throughout the day, being able to detect differences among plots due to canopy biomass and structure and not due to leaf physiology. The slope of the evolution of Tc during the morning was well correlated with stomata conductance and is proposed as a promising indicator to track water status. Its main advantage relative to single-time measurements of temperature is that it encompasses stomatal behavior in response to the evolution of meteorological variables during the day.

\section{Acknowledgments}

This research was funded by Axìa (CRUI-Nestlé project for research and development). AHS and CASI flights were conducted in the frame of EUFAR (European Facility for Airborne Research Project) Transnational Access project. The authors gratefully acknowledge Marchesi, A., Di Mauro, B., Julitta, T., Ferretti, M. (DISAT-UNIMIB, Italy), Bergonti, M. (Università Cattolica di Piacenza), Boschetti, M., Musanti, M. (CNR-IREA Milano), Picchi, V. (CRA, Milano) and Pinto, F. (Forschungszentrum Jülich) for their support during the field campaign.

\section{Author Contributions}

Micol Rossini organized data analysis and wrote the paper with discussions and contributions to interpretations of the results from all co-authors. Cinzia Panigada, Chiara Cilia and Michele Meroni contributed to data interpretation and writing. Cinzia Panigada was the technical coordinator of the campaign and planned the experimental design with Michele Meroni. Lorenzo Busetto processed the thermal images and Sergio Cogliati performed the fluorescence retrieval. Stefano Amaducci was responsible for the experimental field management and Roberto Colombo was the project lead scientist.

\section{Conflicts of Interest}

The authors declare no conflict of interest.

\section{References}

1. Fereres, E.; Orgaz, F.; Gonzalez-Dugo, V. Reflections on food security under water scarcity. J. Exp. Bot. 2011, doi:10.1093/jxb/err165.

2. Jury, W.A.; Vaux, H.J., Jr. The emerging global water crisis: Managing scarcity and conflict between water users. In Advances in Agronomy; Donald, L.S., Ed.; Academic Press: Waltham, MA, USA, 2007; Volume 95, pp. 1-76.

3. Yordanov, I.; Velikova, V.; Tsonev, T. Plant responses to drought, acclimation, and stress tolerance. Photosynthetica 2000, 38, 171-186.

4. Chaves, M.M.; Flexas, J.; Pinheiro, C. Photosynthesis under drought and salt stress: Regulation mechanisms from whole plant to cell. Ann. Bot. 2009, 103, 551-560.

5. Taghvaeian, S.; Chávez, J.; Hansen, N. Infrared thermometry to estimate crop water stress index and water use of irrigated maize in Northeastern Colorado. Remote Sens. 2012, 4, 3619-3637. 
6. Torrion, J.; Maas, S.; Guo, W.; Bordovsky, J.; Cranmer, A. A three-dimensional index for characterizing crop water stress. Remote Sens. 2014, 6, 4025-4042.

7. Idso, S.B.; Jackson, R.D.; Pinter, P.J., Jr.; Reginato, R.J.; Hatfield, J.L. Normalizing the stress-degree-day parameter for environmental variability. Agric. Meteorol. 1981, 24, 45-55.

8. Maes, W.H.; Steppe, K. Estimating evapotranspiration and drought stress with ground-based thermal remote sensing in agriculture: A review. J. Exp. Bot. 2012, 63, 4671-4712.

9. Flexas, J.; Bota, J.; Cifre, J.; Escalona, J.M.; Galmes, J.; Gulias, J.; Lefi, E.K.; Martinez-Canellas, S.F.; Moreno, M.T.; Ribas-Carbo, M.; et al. Understanding down-regulation of photosynthesis under water stress: Future prospects and searching for physiological tools for irrigation management. Ann. Appl. Biol. 2004, 144, 273-283.

10. Gamon, J.A.; Peñuelas, J.; Field, C.B. A narrow-waveband spectral index that tracks diurnal changes in photosynthetic efficiency. Remote Sens. Environ. 1992, 41, 35-44.

11. Panigada, C.; Rossini, M.; Meroni, M.; Cilia, C.; Busetto, L.; Amaducci, S.; Boschetti, M.; Cogliati, S.; Picchi, V.; Pinto, F.; et al. Fluorescence, pri and canopy temperature for water stress detection in cereal crops. Int. J. Appl. Earth Obs. Geoinf. 2014, 30, 167-178.

12. Rossini, M.; Fava, F.; Cogliati, S.; Meroni, M.; Marchesi, A.; Panigada, C.; Giardino, C.; Busetto, L.; Migliavacca, M.; Amaducci, S.; et al. Assessing canopy pri from airborne imagery to map water stress in maize. ISPRS J. Photogramm. Remote Sens. 2013, 86, 168-177.

13. Zarco-Tejada, P.J.; González-Dugo, V.; Williams, L.E.; Suárez, L.; Berni, J.A.J.; Goldhamer, D.; Fereres, E. A pri-based water stress index combining structural and chlorophyll effects: Assessment using diurnal narrow-band airborne imagery and the CWSI thermal index. Remote Sens. Environ. 2013, 138, 38-50.

14. Römer, C.; Wahabzada, M.; Ballvora, A.; Pinto, F.; Rossini, M.; Panigada, C.; Behmann, J.; Léon, J.; Thurau, C.; Bauckhage, C.; et al. Early drought stress detection in cereals: Simplex volume maximisation for hyperspectral image analysis. Funct. Plant Biol. 2012, 39, 878-890.

15. Meroni, M.; Rossini, M.; Guanter, L.; Alonso, L.; Rascher, U.; Colombo, R.; Moreno, J. Remote sensing of solar-induced chlorophyll fluorescence: Review of methods and applications. Remote Sens. Environ. 2009, 113, 2037-2051.

16. Cheng, Y.-B.; Middleton, E.; Zhang, Q.; Huemmrich, K.; Campbell, P.; Corp, L.; Cook, B.; Kustas, W.; Daughtry, C. Integrating solar induced fluorescence and the photochemical reflectance index for estimating gross primary production in a cornfield. Remote Sens. 2013, 5, 6857-6879.

17. Lancashire, P.D.; Bleiholder, H.; Langeluddecke, P.; Stauss, R.; van den Boom, T.; Weber, E.; Witzenberger, A. A uniform decimal code for growth stages of crops and weeds. Ann. Appl. Biol. 1991, 119, 561-601.

18. Prasad, P.V.V.; Staggenborg, S.A.; Ristic, Z. Impacts of drought and/or heat stress on physiological, developmental, growth, and yield processes of crop plants. In Response of Crops to Limited Water: Understanding and Modeling Water Stress Effects on Plant Growth Processes. Advances in Agricultural Systems Modeling Series 1; Ahuja, L.H., Saseendran, S.A., Eds.; ASA-CSSA: Madison, WI, USA, 2008.

19. Cilia, C.; Panigada, C.; Rossini, M.; Meroni, M.; Busetto, L.; Amaducci, S.; Boschetti, M.; Picchi, V.; Colombo, R. Nitrogen status assessment for variable rate fertilization in maize through hyperspectral imagery. Remote Sens. 2014, 6, 6549-6565. 
20. Sumayao, C.R.; Kanemasu, E.T.; Brakke, T.W. Using leaf temperature to assess evapotranspiration and advection. Agric. Meteorol. 1980, 22, 153-166.

21. Bilger, W.; Schreiber, U.; Bock, M. Determination of the quantum efficiency of photosystem-ii and of nonphotochemical quenching of chlorophyll fluorescence in the field. Oecologia 1995, 102, 425-432.

22. Webb, N.; Nichol, C.; Wood, J. User Manual for the Sunscan Canopy Analysis System (2.0 Version); Potter: Cambridge, UK, 2008; p. 83.

23. Van Evert, F.K.; Campbell, G.S. Cropsyst: A collection of object-oriented simulation models of agricultural systems. Agron. J. 1994, 86, 325-331.

24. Gillespie, A.R. Spectral mixture analysis of multispectral thermal infrared images. Remote Sens. Environ. 1992, 42, 137-145.

25. Jackson, R.D. Canopy temperature and crop water stress. Adv. Irrig. 1982, 1, 43-85.

26. Idso, S.B. Non-water-stressed baselines: A key to measuring and interpreting plant water stress. Agric. Meteorol. 1982, 27, 59-70.

27. Irmak, S.; Haman, D.Z.; Bastug, R. Determination of crop water stress index for irrigation timing and yield estimation of corn. Agron. J. 2000, 92, 1221-1227.

28. Smith, G.M.; Milton, E.J. The use of the empirical line method to calibrate remotely sensed data to reflectance. Int. J. Remote Sens. 1999, 20, 2653-2662.

29. Rouse, J.W.; Haas, R.H.; Schell, J.A.; Deering, D.W.; Harlan, J.C. Monitoring the Vernal Advancements and Retro Gradation of Natural Vegetation; Texas A \& M University, Remote Sensing Center: Greenbelt, MD, USA, 1974; p. 371.

30. Rondeaux, G.; Steven, M.; Baret, F. Optimization of soil-adjusted vegetation indices. Remote Sens. Environ. 1996, 55, 95-107.

31. Haboudane, D.; Miller, J.R.; Tremblay, N.; Zarco-Tejada, P.J.; Dextraze, L. Integrated narrow-band vegetation indices for prediction of crop chlorophyll content for application to precision agriculture. Remote Sens. Environ. 2002, 81, 416-426.

32. Gitelson, A.A.; Kaufman, Y.J.; Stark, R.; Rundquist, D. Novel algorithms for remote estimation of vegetation fraction. Remote Sens. Environ. 2002, 80, 76-87.

33. Maier, S.W.; Günther, K.P.; Stellmes, M. Remote Sensing and Modelling of Solar Induced Fluorescence. In Proceedings of the 1st Workshop on Remote Sensing of Solar Induced Vegetation Fluorescence, Noodwijk, The Netherlands, 19-20 June 2002; ESTEC: Noordwijk, The Netherlands, 2002.

34. Zarco-Tejada, P.J.; Berni, J.A.J.; Suárez, L.; Sepulcre-Cantó, G.; Morales, F.; Miller, J.R. Imaging chlorophyll fluorescence with an airborne narrow-band multispectral camera for vegetation stress detection. Remote Sens. Environ. 2009, 113, 1262-1275.

35. Rossini, M.; Meroni, M.; Migliavacca, M.; Manca, G.; Cogliati, S.; Busetto, L.; Picchi, V.; Cescatti, A.; Seufert, G.; Colombo, R. High resolution field spectroscopy measurements for estimating gross ecosystem production in a rice field. Agric. For. Meteorol. 2010, 150, 1283-1296.

36. Pearson, K. On the coefficient of racial likeness. Biometrika 1926, 18, 105-117.

37. Li, Y.; Zhou, J.; Kinzelbach, W.; Cheng, G.; Li, X.; Zhao, W. Coupling a svat heat and water flow model, a stomatal-photosynthesis model and a crop growth model to simulate energy, water and carbon fluxes in an irrigated maize ecosystem. Agric. For. Meteorol. 2013, 176, 10-24. 
38. Gonzalez-Dugo, V.; Zarco-Tejada, P.; Nicolás, E.; Nortes, P.A.; Alarcón, J.J.; Intrigliolo, D.S.; Fereres, E. Using high resolution uav thermal imagery to assess the variability in the water status of five fruit tree species within a commercial orchard. Precis. Agric. 2013, 14, 660-678.

39. Perry, E.M.; Roberts, D.A. Sensitivity of narrow-band and broad-band indices for assessing nitrogen availability and water stress in an annual crop all rights reserved. No part of this periodical may be reproduced or transmitted in any form or by any means, electronic or mechanical, including photocopying, recording, or any information storage and retrieval system, without permission in writing from the publisher. Agron. J. 2008, 100, 1211-1219.

40. Roberts, D.A.; Dennison, P.E.; Peterson, S.; Sweeney, S.; Rechel, J. Evaluation of airborne visible/infrared imaging spectrometer (aviris) and moderate resolution imaging spectrometer (modis) measures of live fuel moisture and fuel condition in a shrubland ecosystem in southern california. J. Geophys. Res. Biogeosci. 2006, 111, G04S02.

41. Çakir, R. Effect of water stress at different development stages on vegetative and reproductive growth of corn. Field Crop. Res. 2004, 89, 1-16.

42. Suárez, L.; Zarco-Tejada, P.J.; Berni, J.A.J.; Gonzalez-Dugo, V.; Fereres, E. Modelling pri for water stress detection using radiative transfer models. Remote Sens. Environ. 2009, 113, 730-744.

43. Suárez, L.; Zarco-Tejada, P.J.; Gonzalez-Dugo, V.; Berni, J.A.J.; Sagardoy, R.; Morales, F.; Fereres, E. Detecting water stress effects on fruit quality in orchards with time-series pri airborne imagery. Remote Sens. Environ. 2010, 114, 286-298.

44. Rossini, M.; Nedbal, L.; Guanter, L.; Ač, A.; Alonso, L.; Burkart, A.; Cogliati, S.; Colombo, R.; Damm, A.; Drusch, M.; et al. Red and far-red sun-induced chlorophyll fluorescence as a measure of plant photosynthesis. Geophys. Res. Lett. 2015, 42, 2014 GL062943.

45. Bellvert, J.; Zarco-Tejada, P.J.; Girona, J.; Fereres, E. Mapping crop water stress index in a 'pinot-noir' vineyard: Comparing ground measurements with thermal remote sensing imagery from an unmanned aerial vehicle. Precis. Agric. 2014, 15, 361-376.

(C) 2015 by the authors; licensee MDPI, Basel, Switzerland. This article is an open access article distributed under the terms and conditions of the Creative Commons Attribution license (http://creativecommons.org/licenses/by/4.0/). 